\title{
Contribuições de Paulo Freire para as práticas pedagógicas de formadores(as) de professores(as) que ensinam Matemática
}

\section{Paulo Freire's contributions to the pedagogical practices of trainers of teachers who teach Mathematics}

\author{
Ainá Montessanti Selingardi ${ }^{1}$ \\ Beatriz de Macêdo Zero ${ }^{2}$ \\ Samanta Margarida Milani3
}

\section{Resumo}

Este trabalho teve por objetivos: evidenciar as contribuições teóricas de Paulo Freire para as práticas pedagógicas de formadores(as) das licenciaturas em Matemática e apresentar possíveis relações entre Educação Matemática e ideias freireanas que levam à reflexão sobre a prática. A questão que direcionou a investigação foi: Quais são as principais contribuições teóricas de Paulo Freire para as práticas pedagógicas dos(as) formadores(as) de professores(as) que ensinam Matemática? Trata-se de uma investigação qualitativa e de caráter bibliográfico em que os dados foram coletados em uma dissertação que contém narrativas de formadores(as) e analisados a partir de conceitos do referencial freireano. Os principais resultados mostram a potencialidade existente nas falas de professores(as) formadores(as) a partir de suas práticas e da percepção do curso em que atuam e que as obras de Paulo Freire podem favorecer o trabalho deste docente, sua formação permanente e as estruturas dos cursos em que se encontram.

Palavras-chave: Formação de Professores. Educação Matemática. Teoria Freireana.

\begin{abstract}
This work aimed to highlight Paulo Freire's theoretical contributions to the pedagogical practices of trainers of Mathematics Degrees and present possible relationships between Mathematics Education and freirean ideas that lead to reflection on practice. The question that guided the investigation was: What are the main theoretical contributions of Paulo Freire to the pedagogical practices of the trainers of mathematics pre-service teachers? This is a qualitative and bibliographical investigation in which data were

\footnotetext{
${ }^{1}$ Doutoranda em Educação Matemática pelo Instituto de Geociências e Ciências Exatas (UNESP) - Câmpus de Rio Claro/SP. Mestra em Ensino de Ciências Exatas pela UFSCar e professora do Instituto Federal de Educação, Ciência e Tecnologia de São Paulo (IFSP) - Câmpus Campinas/SP. Email: aina.montessanti@unesp.br

${ }^{2}$ Doutoranda em Educação Matemática pelo Instituto de Geociências e Ciências Exatas (UNESP) - Câmpus de Rio Claro/SP. Mestra em Educação em Ciências e Matemática pela UFSCar e professora da FHO| Fundação Hermínio Ometto. E-mail: beatriz.zero@unesp.br

3 Doutoranda em Educação Matemática pelo Instituto de Geociências e Ciências Exatas (UNESP) - Câmpus de Rio Claro/SP. Mestra em Matemática em Rede Nacional (PROFMAT), professora do Instituto Federal de Educação, Ciência e Tecnologia de Rondônia (IFRO) - Câmpus Cacoal/RO. Email: samanta.milani@ifro.edu.br
} 


\section{-Revista de Iniciação à Docência, v.6 , n. 2, 2021- \\ Publicação: dezembro, 2021 - ISSN 2525-4332}

collected in a dissertation that contains narratives of trainers and analyzed based on concepts from the freirean framework. The main results show the potential existing in the speeches of teacher trainers from their practices and the perception of the course in which they work and that the works of Paulo Freire can favor the work of this teacher, their ongoing training and structures of the courses they are in.

Keywords: Teacher Training. Mathematics Education. Paulo Freire's Theory.

\section{Motivações e justificativas que levaram à escrita}

Investigações centradas na Formação de Professores(as) sob o viés de uma concepção de docência como um processo de desenvolvimento profissional associado à construção de conhecimentos específicos são marcantes desde a década de 1980 (SHULMAN, 2014). Nesta direção, compreende-se o lecionar como algo não inato, mas que se aprende no decorrer de sua passagem por uma licenciatura e, posteriormente, também em outros espaços e situações ao longo das vivências profissionais.

O lugar do qual falamos situa-se na Formação de Professores(as) que ensinam Matemática: este artigo foi produzido por docentes brasileiras que lecionam conteúdos matemáticos em diferentes lugares: uma atua em um curso de licenciatura em Pedagogia e bacharelado em Psicologia e duas trabalham em Institutos Federais com alunas e alunos do Ensino Médio e do Ensino Superior (licenciatura em Matemática) e Pós-Graduação (Formação de Professores). Tais docentes também assumem o papel de estudantes de Pós-Graduação em Educação Matemática.

Este trabalho também é resultado de leituras, discussões e questionamentos feitos durante a realização de uma disciplina sobre Paulo Freire e Educação Matemática, realizada no primeiro semestre de 2021 no programa de Pós-Graduação em Educação Matemática da Universidade Estadual Paulista (UNESP) - Campus Rio Claro. Tal disciplina promoveu não apenas o encontro das autoras, como modificações em suas percepções sobre a leitura e a escrita de mundo; a Educação Matemática; a Formação de Professores; as vozes com as quais se estabelecem diálogos e, principalmente, as práticas desenvolvidas em sala de aula - espaço que se transferiu para um ambiente virtual devido à Pandemia de Sars-CoV-2.

Ao articular os estudos feitos na disciplina com as práticas pedagógicas de formadores(as) de professores(as) que ensinam Matemática (temática que optamos devido à nossa formação e profissão) foram propostos os seguintes objetivos: evidenciar as contribuições teóricas de Paulo Freire para as práticas pedagógicas de formadores(as) de professores(as) que ensinam Matemática e apresentar aos educadores(as) as possíveis inter-relações entre a Educação Matemática e alguns conceitos freireanos em prol da obtenção de subsídios para refletirem sua formação. Transformando as inquietações em um problema de pesquisa obtivemos a seguinte questão: Quais são as 


\title{
-Revista de Iniciação à Docência, v.6 , n. 2, 2021- \\ Publicação: dezembro, 2021 - ISSN 2525-4332
}

principais contribuições teóricas de Paulo Freire para as práticas pedagógicas dos(as) formadores(as) de professores(as) que ensinam Matemática?

Trata-se de uma investigação de abordagem qualitativa (SEVERINO, 2007, p. 119), do tipo pesquisa bibliográfica. Para Severino (2007, p. 122, grifo do autor):

\begin{abstract}
A pesquisa bibliográfica é aquela que se realiza a partir do registro disponível, decorrente de pesquisas anteriores, em documentos impressos como livros, artigos, teses etc. Utiliza -se de dados ou de categorias teóricas já trabalhados por outros pesquisadores e devidamente registrados. Os textos tornam-se fontes dos temas a serem pesquisados. O pesquisador trabalha a partir das contribuições dos autores dos estudos analíticos constantes dos textos.
\end{abstract}

Acerca da definição de procedimentos metodológicos a se adotar neste tipo de pesquisa, Lima e Mioto (2007, p. 39-42) apresentam três passos: 1. "A exposição do método": momento em que o método deve ser selecionado; 2. Definição dos procedimentos: momento em que as estratégias devem ser planejadas e efetivadas; 3 . “[...] apresentação do percurso de pesquisa".

Como Lima e Mioto (2007) assumimos o método dialético para realizarmos o trabalho, pois mediante excertos de narrativas de professores(as) formadores(as) sobre suas práticas pedagógicas, encontrados na dissertação de Zero (2020), tentamos compreender quem são esses profissionais e o que pensam sobre o que fazem, a partir de uma perspectiva dialética e assim a análise das falas se fez por meio de categorias estabelecidas por meio de conceitos freireanos. É importante dizer que as autoras assumem que não tiveram a intenção de levar o(a) leitor(a) ao entendimento desse sujeito (professor(a) formador(a)) como um profissional homogêneo, nem de tentar explicar logicamente suas práticas profissionais apresentando possíveis razões pelas quais as desenvolvem, mas objetivou-se compreender o que pensam e aproximar tais pensamentos das propostas freireanas.

Como parte da investigação bibliográfica, foram realizadas as leituras das seguintes obras: Professora sim, tia não: cartas a quem ousa ensinar (1993a); Política e Educação (1993b), Paulo Freire: Uma biobibliografia (1996); Pedagogia da autonomia: saberes necessários à prática docente (2005); Direitos Humanos e Educação Libertadora (2020a) e Pedagogia do Oprimido (2020b). Além dos escritos de Paulo Freire e/ou embasados em suas ideias, outros trabalhos discutidos neste artigo foram o livro de Gadotti et al. (1996) que traz a bibliografia de Paulo Freire e o texto de Forner e Malheiros (2020) lido no decorrer da disciplina da pós-graduação.

Como justificativa da seleção das práticas do(a) professor(a) formador(a) um dos objetos de investigação deste trabalho, tudo começou com a leitura do "Mapeamento da pesquisa acadêmica sobre o professor que ensina Matemática: período 2001-2012" (FIORENTINI; PASSOS; LIMA, 2016), documento que apresenta um panorama de pesquisas dessa temática produzidas nos últimos anos. Na produção acadêmica brasileira 


\section{-Revista de Iniciação à Docência, v.6 , n. 2, 2021- \\ Publicação: dezembro, 2021 - ISSN 2525-4332}

em Educação Matemática o professor que ensina Matemática (PEM) também é um considerado um " [...] campo de estudo" (FIORENTINI; PASSOS; LIMA, 2016, p. 18) no qual investigadores(as) e cursos de Pós-Graduação têm se debruçado para identificar suas especificidades e apontar caminhos para o reconhecimento de suas práticas.

Em tal mapeamento, os(as) pesquisadores(as) apresentam diversos sub-campos de pesquisas sobre o PEM, pois os(as) professores(as) que ensinam Matemática possuem distintas formações e podem atuar em diferentes áreas e momentos educacionais, como em cursos de formação inicial e/ou formação continuada. Em busca de explorar as especificidades de um tipo de professor(a) que ensina Matemática, com base na experiência recente de uma das autoras que em sua dissertação estudou a respeito do(a) formador(a) e suas práticas, as pesquisadoras envolvidas compreenderam que se tratava tanto de uma possibilidade, quanto de uma necessidade, investigar mais a respeito deste profissional - o(a) professor(a) formador(a) - aproximando tal busca no contexto em que se situavam naquele momento (estudando Paulo Freire e Educação Matemática na disciplina de pós-graduação).

O trabalho de Coura e Passos (2017) denominado "Estado do conhecimento sobre o formador de professores de Matemática no Brasil” também respaldou a escolha pelo(a) professor(a) formador(a) neste trabalho. Essa investigação de Coura e Passos (2017), derivada do mapeamento organizado por Fiorentini, Passos e Lima (2016), se constituiu da leitura de 30 pesquisas, dentre as quais, cinco delas se tornaram especialmente de nosso interesse por enfatizarem as práticas dos(as) formadores(as) de professores (as) que ensinam Matemática - Pinheiro (2008); Pamplona (2009); Komatsu (2010); Cavalcante (2011) e Janzen (2011). Embora os dados aqui analisados sejam oriundos da dissertação de Zero (2020), os trabalhos encontrados na pesquisa de Coura e Passos (2017) nos ajudaram a compreender um pouco mais sobre o que fora produzido a respeito do(a) formadora(a) e suas práticas.

Vale ressaltar que todos os trabalhos mencionados sobre a prática dos(as) formadores(as) de professores(as) não se apoiaram no referencial freiriano, sendo este um exercício realizado neste artigo, considerando os objetivos apresentados, trazendo à tona as dimensões sobre como as perspectivas freireanas contribuem para dialogar e problematizar os aspectos investigados e anunciados nos trabalhos lidos, tanto aqueles encontrados em Coura e Passos (2017), quanto na dissertação de Zero (2020)

É importante também indicar que conforme Fiorentini, Passos e Lima (2016, p. 19) "O professor que ensina Matemática é um campo emergente de pesquisa" e dessa maneira escolhemos a pesquisa bibliográfica como forma de prosseguir e consolidar o presente artigo visando trazer a perspectiva freireana às discussões teóricas e práticas em investigações desse campo em ascensão.

No presente artigo inicialmente abordamos o histórico de Paulo Freire e aspectos bibliográficos acerca da formação de professores(as), em seguida discutimos algumas 


\section{-Revista de Iniciação à Docência, v.6 , n. 2, 2021- \\ Publicação: dezembro, 2021 - ISSN 2525-4332}

práticas pedagógicas de formadores(as) de professores(as) que ensinam Matemática, apresentamos na sequência as características desses professores(as) e finalizamos com as considerações da pesquisa bibliográfica realizada.

\section{Paulo Freire: aspectos biográficos, históricos e possíveis relações com a formação de professores(as).}

Paulo Reglus Neves Freire (1921-1997), teve e tem seu nome difundido no Brasil e em outros países, assim como desempenhou diferentes papéis durante sua vida, deixando uma produção bibliográfica e ações que ainda são objetos de análise e reflexão para profissionais como os(as) educadores(as), filósofos(as) e sociólogos(as).

Paulo Freire foi alfabetizado por sua mãe, escrevendo com gravetos das mangueiras e concluiu sua escolarização primária em Jaboatão (cidade próxima à Recife). Na cidade de Recife foi acolhido pelo Colégio Oswaldo Cruz, onde completou os estudos secundários e pré-jurídicos e, aos 22 anos, ingressou na Faculdade de Direito do Recife. Antes de concluir os estudos universitários Paulo Freire tornou-se professor de Língua Portuguesa do mesmo colégio.

Após tal experiência como docente, Paulo Freire assumiu a direção e superintendência do SESI (Serviço Social da Indústria) de 1947 a 1957, período em que teve contato com a educação de adultos/trabalhadores. Posteriormente, fundou no Recife, ao lado de outros educadores e interessados, o Instituto Capibaribe "Instituição de ensino privado conhecida até hoje em Recife pelo seu alto nível de ensino e de formação científica, ética e moral voltada para a consciência democrática." (GADOTTI et al., 1996, p. 33).

No Ensino Superior iniciou sua experiência docente como professor de Filosofia da Educação na Escola de Serviço Social, posteriormente incorporada à Universidade do Recife. Em 1959 obteve o título de Doutor em Filosofia e História da Educação, defendendo a tese "Educação e atualidade brasileira" e foi nomeado na Faculdade de Filosofia, Ciências e Letras da Universidade do Recife, onde se tornou livre docente no ano seguinte.

Envolvido no Programa Nacional de Alfabetização, Freire falava em educação social. O "Método Paulo Freire" e suas ideias já se faziam propagar por um caminho autenticamente popular no final da década de 1950. No início dos anos 1960 foi um dos fundadores do "Movimento de Cultura Popular do Recife", sobre o qual Gadotti et al. (1996) afirmam que marcou a formação profissional política e afetiva do educador pernambucano.

Segundo Gadotti et al. (1996) Paulo Freire organizou e dirigiu a campanha de alfabetização de Angicos - RN, onde ficou conhecido como educador voltado para questões do povo e recebeu, em função disso, o convite do Ministro da Educação Paulo de Tarso Santos, do governo Goulart para realizar uma campanha nacional de 


\title{
-Revista de Iniciação à Docência, v.6 , n. 2, 2021- \\ Publicação: dezembro, 2021 - ISSN 2525-4332
}

alfabetização. O Programa Nacional de Alfabetização foi extinto em 1964 pelo governo militar e Paulo Freire obteve asilo na Bolívia, país que também sofreu um golpe de estado, o que levou Freire a ter asilo político no Chile, no mesmo ano.

Em 1969 recebeu o convite para lecionar nos Estados Unidos e trabalhar no Conselho Mundial das Igrejas. O Conselho permitiu que Paulo Freire visitasse diferentes países do mundo, onde ajudou a sistematizar planos de educação popular. Na Suíça lecionou para alunos(as) da Faculdade de Educação na Universidade de Genebra (GADOTTI et al., 1996).

Sua trajetória e obra foram desenvolvidas em meio a esses episódios históricos que envolveram drásticas mudanças sociais que resultaram em seu exílio, devido às suas ações voltadas para a alfabetização crítica de adultos trabalhadores, por exemplo:

\begin{abstract}
O golpe militar, em 1964, deixou claro que esta não era a educação que desejava para o Brasil, e Paulo Freire, depois de passar um período na prisão, viveu como exilado na Bolívia, Chile, nos Estados Unidos e, finalmente, na Suíça. Foi ali que, durante quase uma década, de 1970 até 1979, tornou-se um educador do mundo, assessorando práticas educativas realizadas por igrejas e movimentos sociais em todos os continentes. De volta ao Brasil, reassumiu seu trabalho na universidade (na Universidade de Campinas e na Pontifícia Universidade Católica de São Paulo), sem perder contato com experiências pedagógicas de movimentos sociais, e em geral, das classes subalternas. Foi com este espírito que se sentiu desafiado a assumir o cargo de secretário de Educação no município de São Paulo (1989-1991). (STRECK, 2010, p. 329-330).
\end{abstract}

Em 1979 retornou para o Brasil, onde atuou como professor da PUC-SP (Pontifícia Universidade Católica de São Paulo). No ano seguinte tornou-se professor da UNICAMP (Universidade Estadual de Campinas), onde lecionou até 1990. Paulo Freire trabalhou como secretário de Educação durante a gestão democrática da educação pública na cidade de São Paulo de 1989 a 1991. Além dos impactos decorrentes de suas ações e experiências nos diversos lugares por onde passou, seus escritos trazem concepções sobre temas como educação, humanização e política, afinal, segundo sua perspectiva, nossas práticas educacionais não apenas carregam essa caracterização política, mas o são políticas em sua essência: "A impossibilidade da neutralidade da educação que resulta dessa qualidade que a educação tem de ser política, não necessariamente partidária, obviamente, mas a qualidade que a educação tem de ser política (FREIRE, 2020, p. 34)”.

Ainda falando sobre educação e a prática do professor (concepção de ensino), Freire (2005, p. 23) diz que: “É nesse sentido que ensinar não é transferir conhecimentos, conteúdos nem formar é ação pela qual um sujeito criador dá forma, estilo ou alma a um corpo indeciso e acomodado". Afirma ainda que, enquanto formador(a) de professores(as), deve falar da construção do conhecimento envolvendo os(as) alunos(as) na prática e na teoria.

Notamos a importância da relação dialógica entre os envolvidos no processo de ensino e aprendizagem quando observamos em Freire (2020b) que para ser autêntica a educação não se faz de $A$ para $B$, mas de $A$ com $B$, mediatizados pelo mundo. 


\section{-Revista de Iniciação à Docência, v.6 , n. 2, 2021- \\ Publicação: dezembro, 2021 - ISSN 2525-4332}

Professores(as) durante suas carreiras se deparam com tempos diferentes, educandos(as) diferentes e mundos diferentes, assim a atividade docente se encontra em constante mudança:

Nada do que experimentei em minha atividade docente deve necessariamente repetir-se [...] Minha franquia ante os outros e o mundo mesmo e a maneira radical como me experimento enquanto ser cultural, histórico inacabado e consciente do inacabamento (FREIRE, 2005, p. 50).

Para que essa mudança proporcione aos educandos(as) uma educação libertadora, o(a) educador(a) precisa estar sempre disponível para o diálogo. Segundo Freire (2005, p. 137), a formação dos(as) professores(as) deve ser constituída da importância que os aspectos ecológico, social e econômico em que vivemos têm sobre nós. Ele afirma ainda que a indagação, a busca e a pesquisa fazem parte da natureza da prática docente e ressalta que o(a) professor(a) precisa se perceber e se assumir pesquisador(a). Essa práxis é decorrente do pensar certo e envolve o diálogo e o movimento dinâmico entre o fazer e o pensar sobre o fazer.

A formação de professores(as) deve ser realizada de forma permanente. Sobre a formação permanente e reflexão sobre a prática, lemos “[...] na formação permanente dos professores, o momento fundamental é o da reflexão crítica sobre a prática, a curiosidade ingênua, percebendo-se como tal, se vá tornando crítica" (FREIRE, 2005, p. 39). Para articular a formação e a atuação do(a) formador(a) de PEM com as ideias freireanas, é necessário pensar que tal professor(a), ao assumir o papel de formador(a), não apenas ensina ou deposita conteúdos matemáticos nos(as) licenciandos(as), pois a influência destes também impacta a prática e a essência daqueles, já que:

[...] quem forma se forma e re-forma ao formar e quem é formado forma-se ao ser formado. É nesse sentido que ensinar não é transferir conhecimentos, conteúdos nem formar é ação pela qual um sujeito criador dá forma, estilo ou alma a um corpo indeciso e acomodado. (FREIRE, 2005, p. 23).

Freire (2005, p. 92) ressalta a importância da qualificação profissional do(a) professor(a) e argumenta que o(a) professor(a) deve estudar e levar a sério sua formação para ter força moral para coordenar as atividades de sua classe. Durante o período em que foi secretário da Educação, propôs a reorientação curricular que envolvia diversos aspectos para implementação da educação pública popular, que visava à formação do sujeito social e que tivesse um projeto pedagógico emancipador. Entre esses aspectos vamos abordar a formação permanente dos(as) professores(as) da rede municipal de ensino.

Uma das preocupações centrais de nossa administração não poderia deixar de ser a formação permanente da educadora. Não se pode pensar em mudar a cara da escola, não se pode pensar em ajudar a escola a ficar séria, rigorosa, competente e alegre sem pensar na formação permanente da educadora. (FREIRE, 2020a, p.91).

Lemos em Forner e Malheiros (2020, p. 503) que Freire "faz uso do termo formação permanente, por entender que o ser humano se encontra em construção, ou 


\section{-Revista de Iniciação à Docência, v.6 , n. 2, 2021- \\ Publicação: dezembro, 2021 - ISSN 2525-4332}

seja, inacabado, em busca de sua completude". Em Freire (2020a) também observamos que a proposta de formação permanente se realizava a partir de diálogos em torno da prática docente, na reflexão sobre a prática, com base na ação-reflexão-ação. Também foram incluídos nos programas de formação, cursos de curta duração, conferências e intercâmbios para troca de experiências. Os trabalhos de reorientação e de formação permanente tinham a supervisão de professores(as) universitários(as) da USP, Unicamp e PUC-SP.

Freire (2020a) relata que o processo de formação permanente dos(as) professores(as) têm como base a reflexão sobre a prática e se dá a partir do diálogo em torno destas. Percebemos então, por meio desta relação dialógica, que a formação permanente permitiria a apropriação da realidade $\operatorname{dos}(a s)$ professores(as) e traria a eles(as) a sensação de pertencimento.

Forner e Malheiros (2020) trazem reflexões sobre a experiência com formação de professores(as) de Matemática sob uma perspectiva freireana, em que o curso é elaborado com professores(as) e não para professores(as). Ressaltam que a essência do curso tem as relações fundamentadas no diálogo e na colaboração, como ocorreu nos cursos de formação propostos durante o período em que foi secretário de educação da cidade de São Paulo, que observamos em Freire (2020a).

Após introduzirmos um resumo de fatos históricos sobre a vida de Freire e mencionarmos alguns de seus conceitos pautados na formação docente, vamos evidenciar essas contribuições teóricas a aspectos relativos à Educação Matemática e à prática dos(as) formadores(as) de professores(as) que ensinam Matemática.

\section{$\mathrm{O}(\mathrm{a})$ formador(a) de professores(as) que ensinam Matemática e suas práticas pedagógicas: uma breve discussão de algumas investigações já efetivadas}

Primeiramente iremos situar o(a) leitor(a) em relação ao que estamos entendendo por formador(a) de professores(as)": nesta pesquisa, estamos nos referindo ao(a) professor(a) que leciona em cursos do Ensino Superior, especificamente em licenciaturas, ou seja, aqueles que atuam na formação inicial de professores(as) que ensinam Matemática na Educação Básica. O(a) formador(a) tem uma importante responsabilidade, pois “[...] durante suas aulas, realiza um trabalho muito parecido com o que o(a) licenciando(a) presenciou quando aluno(a) na Educação Básica e com o que pode realizar quando for lecionar" (COURA; PASSOS, 2017, p. 9).

Embora esta investigação se concentre nos dados de uma dissertação de mestrado de uma das autoras (ZERO, 2020) que contém narrativas de formadores(as), outras cinco pesquisas sobre as práticas deste tipo de professor(a) encontradas na pesquisa de Coura e Passos (2017) também foram fundamentais para complementar a compreensão sobre aspectos deste(a) profissional, seu trabalho e o que pensa a respeito dele. Além de escolher investigar elementos que constituem o(a) professor(a) formador(a), os autores consideraram aspectos de sua trajetória e experiências 


\section{-Revista de Iniciação à Docência, v.6 , n. 2, 2021- \\ Publicação: dezembro, 2021 - ISSN 2525-4332}

acadêmicas e profissionais e optaram por explanar sobre a atuação e as práticas pedagógicas deste(a) professor(a) em uma relação dialógica com os ensinamentos deixados pelo educador Paulo Freire.

Quando voltamos nosso olhar para o(a) formador(a) de professores(as) que ensinam Matemática, foi necessário pensar a respeito de quem é esse formador, o que faz (antes, durante e depois de suas aulas) e algumas das possíveis repercussões de suas ações (quais imagens e percepções ele gera; como aborda os conteúdos de sua área; como se relaciona com os/as estudantes e com seus pares). Entende-se que não se trata de um sujeito profissional homogêneo e/ou que possui o mesmo tipo de formação acadêmica, pois há docentes que ministram disciplinas nesta licenciatura e que não possuem formação pedagógica (ZERO, 2020).

O texto de Coura e Passos (2017) denominado "Estado do conhecimento sobre o formador de professores de Matemática no Brasil” teve por referência as 858 pesquisas (dissertações e teses) apresentadas no Mapeamento sobre o PEM - texto já mencionado neste artigo (FIORENTINI; COURA; PASSOS, 2016) - e dentre essas, 30 estudos, sendo 17 dissertações de mestrado acadêmico, duas de mestrado profissional e 11 teses de doutorado, compuseram o corpus de análise da pesquisa. As autoras deixam claro que os 30 trabalhos analisados tiveram foco majoritariamente no(a) formador(a) de professores(as) que realizaram seus estudos em cursos de Pós-Graduação, mesmo que tivessem cursado licenciatura em sua formação inicial. Assim, no Brasil observava-se um perfil representativo de formadores(as) "[...] voltada para os conteúdos circunscritos à área de conhecimento da Matemática, com pouca interlocução com aspectos relacionados ao ensinar e ao aprender e com a formação de professores". (COURA; PASSOS, 2017, p. 12).

Coura e Passos (2017), inicialmente, analisaram, organizaram e dividiram os 30 trabalhos em dois grupos temáticos: "[...] atuação ou pensamento do formador de professores de matemática" e "[...] formação, aprendizagem, desenvolvimento ou constituição profissional do formador de professores de matemática" (p. 12). Dentre esses, as autoras encontraram 17 estudos que se encaixavam no primeiro grupo e 13 no segundo. Considerando as 17 pesquisas apresentadas, cinco delas focalizam as práticas dos(as) formadores(as) de professores (as) que ensinam matemática - Pinheiro (2008); Pamplona (2009); Komatsu (2010); Cavalcante (2011) e Janzen (2011).

O período de pesquisas estudado por Coura e Passos (2017) se deu entre os anos de 2001 a 2012 - de acordo com o mapeamento de Fiorentini, Passos e Lima (2016), sendo que as cinco investigações aqui mencionadas estão entre 2008 e 2011. Outra pesquisa recente sobre a temática (ZERO, 2020) também será aqui acrescentada, sendo que a análise será centrada em alguns dados de tal investigação, o que se justifica pelas narrativas de professores(as) formadores(as) sobre o que pensam a respeito do que fazem. 


\section{-Revista de Iniciação à Docência, v.6 , n. 2, 2021- \\ Publicação: dezembro, 2021 - ISSN 2525-4332}

Para Freire (2005), a formação de professores(as) é algo permanente, devido a sua consciência de inacabamento, sendo importante que se assuma que "quem forma se forma e re-forma ao formar e quem é formado forma-se e forma ao ser formado" (p. 23). Neste sentido, formar é muito mais que transferir conhecimento, no intuito de simplesmente repassar um conteúdo e treinar os(as) licenciandos(as) para ter um bom desempenho em determinadas atividades e assim ser um bom profissional.

Corroborando com Freire (2005), Coura e Passos (2017) trazem que “[...] o formador é, ele próprio, um professor que também se forma no exercício da profissão, pois precisa mobilizar seus conhecimentos para empreender práticas que atendam às demandas do seu contexto profissional" (p. 9). O que vem ao encontro dos ensinamentos de Freire, tendo em vista que "quem ensina aprende ao ensinar e quem aprende ensina ao aprender" (p. 25).

É importante ressaltar que independente da disciplina que ministram, todo e qualquer professor(a) universitário(a) é responsável pela formação do licenciando(a), mesmo que lecione disciplinas específicas do curso, como:

[...] Cálculo, Análise ou Álgebra, o futuro professor não apenas aprende uma certa matemática, como é esperado pelo formador, mas aprende também um modo de estabelecer relação com o conhecimento; internaliza também um modo de concebê-lo, de tratá-lo e de avaliá-lo no processo de ensino e aprendizagem (OLIVEIRA; FIORENTINI, 2013, p. 926).

Ao pensarmos nas especificidades de um curso de licenciatura, certa responsabilidade é exposta e encontra-se latente: não cabe ao licenciando(a) dominar apenas o conteúdo, mas desenvolver conhecimentos que o levem a saber ensinar (SHULMAN, 1986, 1986). Além disso, as concepções de aprendizagem trazidas por um(a) professor(a) fundamentam o que este faz:

Acredito que o professor ensina coerente com seu conceito de aprendizagem; mesmo que esse conceito não seja assumido no plano da consciência. Eu diria, de maneira ainda mais radical, que o professor não pode ensinar diferentemente de seu conceito de aprendizagem; por mais que se esforce (BECKER, 2008, p. 55).

Dessa maneira, é possível questionar: quais concepções de aprendizagem fundamentam a prática de ensino dos(as) formadores(as)? Estaria o trabalho dos(as) formadores(as) fundamentado em quais pilares sociais e políticos? Tal formador(a) reconhece o espaço da sala de aula da educação básica como uma possibilidade concreta de atuação de seus alunos(as) como futuros(as) professores(as)? Longe de esgotar tais perguntas, o intuito desta investigação também é problematizar o que se verifica na fala dos(as) formadores(as) e buscar indicativos do que tem sido feito e pensado a respeito dessas ações pedagógicas, entendendo-as não como práticas isoladas, mas situadas dentro de estruturas (licenciaturas).

Freire menciona a importância da competência técnica na atuação docente e reconhece que embora seja relevante, não é isolada de posicionamento político e social 


\section{-Revista de Iniciação à Docência, v.6 , n. 2, 2021- Publicação: dezembro, 2021 - ISSN 2525-4332}

por parte do(a) professor(a), ou seja, a forma como esse(a) docente se assume politicamente no mundo tem relação com a prática que ele(a) exerce:

Este professor, para ser consistente na sua prática com a sua opção política, tem, em primeiro lugar, que ser um professor competente. Aliás, num parênteses, eu diria que possivelmente só aí podem os dois coincidir, o professor reacionário e o professor progressista, ambos têm que ser competentes, têm que ensinar realmente (FREIRE, 2020, p. 36).

Embora as temáticas envolvendo $\mathrm{o}(\mathrm{a})$ docente que ensina Matemática não tenham sido o foco das investigações de Paulo Freire, o ensino desta disciplina é tomado como exemplo, visando mostrar como os conteúdos e sua forma de trabalhá-los com os(as) estudantes não estão isolados de características políticas e sociais:

A inviabilidade da dicotomia entre conteúdos, métodos e objetivos, por exemplo, quer dizer, o meu sonho tem que ver com o conteúdo e os métodos de tratar estes conteúdos: eu não posso tratar o mesmo conteúdo da mesma forma que um professor reacionário trata. Eu não quero dizer que para um professor reacionário de matemática, por exemplo, quatro vezes quatro seja quinze, porque num sistema decimal é sempre dezesseis. Mas há uma série de implicações nesse quatro vezes quatro, dezesseis, que tem a ver com as posturas político-ideológicas do professor, que não cabe aqui discutir (FREIRE, 2020, p. 36-37).

Como o diálogo, a palavra e a questão da dialética - com ênfase na totalidade (FREIRE, 2018, p. 191) - são elementos nos quais Paulo Freire se debruçou com bastante aprofundamento, pensamos que seja necessário ouvir o que formadores(as) têm a dizer sobre o que fazem ao invés de apenas pretensiosamente ousarmos analisar sua prática como meras observadoras.

Em Zero (2020) quatro formadores(as) que atuam em licenciaturas em Matemática de diferentes universidades públicas brasileiras, falam sobre diversos elementos de seu trabalho pedagógico, direcionados, a princípio, por um questionário e por uma entrevista. Como no caso da pesquisa em questão, o referencial se encontrava na base de conhecimentos docentes proposta por Shulman em 1987 os instrumentos de coleta de dados foram direcionados por tal base. Para ele, os(as) docentes possuem ao menos sete conhecimentos: conhecimento do conteúdo; conhecimento pedagógico geral; conhecimento do currículo; conhecimento pedagógico do conteúdo; conhecimento dos alunos e suas características; conhecimento de contextos educacionais e conhecimento dos fins, propósitos e valores da educação. (SHULMAN, 2014, p. 206). Freire (2005), em Pedagogia da autonomia, realiza um exercício bastante similar ao indicar alguns saberes docentes essenciais, como o reconhecimento pelo(a) professor(a) do papel discente no processo de aprendizagem, a necessidade de bom senso, a contextualização dos conteúdos com o desvelamento da realidade, etc.

Para a discussão no presente artigo, selecionamos três temas oriundos das falas dos(as) formadores(as) da pesquisa de Zero (2020): disciplinas ministradas; um exemplo de narrativa sobre o ensino de conteúdos matemáticos e as diferentes formações dos(as) formadores(as); e dois exemplos de narrativas sobre a compreensão dos "fins, 


\section{-Revista de Iniciação à Docência, v.6 , n. 2, 2021- \\ Publicação: dezembro, 2021 - ISSN 2525-4332}

propósitos e valores da educação" (SHULMAN, 2014, p. 206) sendo esta uma das categorias da base de conhecimentos de Shulman. A seleção desses temas ocorreu visando situar brevemente o que os(as) formadores(as) lecionam e o que pensam sobre a Matemática e sobre a Educação. Outros detalhes e falas podem ser encontrados diretamente na dissertação, porém para o delineamento deste texto, acreditamos que o conteúdo selecionado seja suficiente para fomentar e propor uma breve discussão com base em aspectos do referencial teórico freireano, cientes de que seria impossível e até mesmo incoerente finalizar ou esgotar o assunto, visto que a impermanência e o inacabamento do ser, como bem discorre Freire (2005), também fazem parte de nossas ideias.

\section{Algumas características dos(as) professores(as) formadores e suas práticas pedagógicas.}

Percebe-se, de acordo com a Figura 1, que os docentes lecionam diferentes conteúdos e disciplinas nas licenciaturas em Matemática de suas universidades, sendo possível identificar por meio de suas nomenclaturas que algumas se voltam mais aos conteúdos matemáticos em si (exemplos: Desenho Geométrico - docente Isaque e Cálculo - docente Renê), enquanto outras articulam conteúdos matemáticos e ensino (exemplos: Informática aplicada ao ensino - docente Renê e Práticas de ensino - docente Sofia). Esses quatro sujeitos correspondem a uma amostra de professores(as) formadores que responderam a um questionário e posteriormente foram convidados a participarem da entrevista que aprofundou questões do primeiro instrumento.

Figura 1: Disciplinas lecionadas por quatro docentes formadores das licenciaturas em Matemática, participantes da pesquisa de Zero (2020)

\begin{tabular}{|l|l|}
\hline Docente & Disciplinas lecionadas \\
\hline Euclides & $\begin{array}{l}\text { Disciplinas que envolvem resolução de problemas; questões tecnológicas; planejamento de } \\
\text { aulas; planos de ensino; planejamento de bimestres. }\end{array}$ \\
\hline Isaque & $\begin{array}{l}\text { Desenho geométrico; Geometria Espacial; Geometria Plana; Teoria dos Números; outras } \\
\text { disciplinas relacionadas ao Ensino de Matemática. }\end{array}$ \\
\hline Renê & $\begin{array}{l}\text { Cálculo; Estágio; Fundamentos da Matemática; Informática aplicada ao ensino; } \\
\text { Instrumentação de ensino; Metodologia de ensino de Matemática; Pesquisa em Educação } \\
\text { Matemática. }\end{array}$ \\
\hline Sofia & \begin{tabular}{l} 
Desenho geométrico; Estágio; História da Matemática; Práticas de ensino. \\
\hline
\end{tabular} \\
\hline
\end{tabular}

Fonte: Zero (2020, p. 45)

A abordagem que tais docentes dão ao ensino de conteúdos matemáticos, os conceitos e aspectos destacados nestas disciplinas, bem como se há uma preocupação com a realidade, com a transformação desta e se existe relação entre os conteúdos e sua 


\section{-Revista de Iniciação à Docência, v.6 , n. 2, 2021- \\ Publicação: dezembro, 2021 - ISSN 2525-4332}

localização no mundo por meio de exemplos que tragam sentido aos estudantes, são vestígios que encontramos no trabalho em questão (ZERO, 2020) e talvez novas investigações possam levar ao aprofundar sobre a perspectiva dos(as) formadores a respeito de outros aspectos presentes em seu trabalho e seu contexto.

Embora na dissertação de Zero (2020), fragmentos das entrevistas dos quatro docentes formadores(as) possam ser encontrados, selecionamos apenas a fala de uma docente, pois ela traz elementos que abrem margem a certas reflexões:

Excerto 1 - Fala da docente Sofia: Eu acho que se as disciplinas matemáticas abordassem a Matemática de diferentes formas ou com diferentes abordagens, estaria para "mais de bom", porque daí esse aluno vai ter essa experiência, porque eu acho e às vezes, pode até parecer uma visão meio limitada - mas ok, é o que eu penso - eu acho que a disciplina matemática tem que dar conta da formação matemática. Claro que pode ser, deve ser, é importante que seja utilizando diferentes abordagens, mas o foco dela é a formação matemática.

Quem tem a função de fazer uma relação entre este conteúdo matemático e o ensino somos nós, nas disciplinas de prática, e a gente não pode, no meu entendimento, delegar isso a ninguém, em especial delegar isso a um professor formador que não tem formação para isso. A gente tem que ter cuidado ao delegar funções para pessoas que não têm a formação. Então como é que eu quero que um professor de "Cálculo" aborde questões relativas ao ensino de Matemática na educação básica se muito provavelmente ele nunca deu aula na educação básica, ele não fez um curso de licenciatura. Isso é complicadíssimo, eu estou delegando uma função para uma pessoa que não tem formação! A não ser que você tenha um corpo docente muito diferenciado em que o professor de determinadas disciplinas matemáticas tem uma formação em licenciatura ou tenha uma experiência na educação básica, a gente não pode delegar isso a eles, assim como não pode delegar a mim a função de ensinar "Análise", por exemplo, eu não tenho formação para isso. Seria complicado se eu tivesse que dar aula de "Análise". Eu daria? Daria, mas seria complicado. Um professor de "Cálculo" ter que trabalhar com essas questões do ensino de Matemática, ele faz? Faz, mas não é o mais adequado, por isso que a gente tem essa diferenciação no nosso curso - disciplina matemática, disciplina de educação matemática. E eu acho que se as disciplinas matemáticas dão uma boa base matemática para os nossos estudantes, a nossa função [dos professores das disciplinas de prática de ensino] é fazer a relação entre ela e a Matemática da Educação Básica. Se não está bem feito, a culpa é nossa. (ZERO,2020, p. 52-53)

Segundo a fala da docente Sofia, podemos identificar e sintetizar duas grandes considerações: a Matemática precisa ser priorizada em disciplinas voltadas a esses conteúdos e há docentes sem formação pedagógica que atuam nessas licenciaturas e dessa forma, não pode existir certa responsabilização pela ausência de articulação entre conteúdo e realidade educacional.

Embora o último aspecto acima mencionado seja um fato (a existência de formação de formadores sem fundamentação pedagógica), isso nos remete a um problema histórico no campo educacional: o modelo $3+1$ (em que um professor realizava três anos de disciplinas de conteúdos específicos e um ano de disciplinas pedagógicas) tenha sido superado legalmente, na prática e de acordo com "Uma análise atenta dos currículos da formação inicial do professor de matemática no Brasil nos leva à seguinte conclusão: a licenciatura saiu do 3+1, mas o 3+1 ainda não saiu da licenciatura" (MOREIRA, 2012, p. 1137).

De acordo com o excerto de Sofia, Pinheiro (2008, p. 139) acrescenta que “[...] o professor sempre esteve voltado para desenvolver as competências dos alunos no 


\section{-Revista de Iniciação à Docência, v.6 , n. 2, 2021- \\ Publicação: dezembro, 2021 - ISSN 2525-4332}

sentido de aprendizagem dos conteúdos (...). Não se percebeu a ação pedagógica do professor observada no sentido de exploração desses conteúdos". A referida autora enfatiza, por exemplo, que o licenciando, durante as aulas da disciplina de Desenho Geométrico, aprimorou conhecimentos relativos à sua percepção geométrica - de forma apenas conteudista - porém não alcançou um crescimento em relação à transposição desses aprendizados para o ensino.

Nessa mesma visão, a pesquisa de Pamplona (2009) ressalta que nas práticas de formação em relação a disciplinas específicas do curso, neste caso Estatística, do professor formador, também estão sobrepostas práticas de formação pedagógica, “[...] visto que um professor que esteja envolvido com o ensino da Estatística - ou de qualquer outra matéria específica - mesmo que não tenha consciência disto, em seu fazer cotidiano, realiza práticas pedagógicas e produz saberes acerca delas” (p. 16).

A partir dessas considerações, notamos que ainda há fortes indícios dicotômicos entre a maneira de ensinar Matemática na Licenciatura e o que se espera do ensinar Matemática na Educação Básica e, não podemos nos esquecer que "[...] um matemático profissional não é um não-educador matemático, do mesmo modo que um educador matemático não é um não-matemático profissional” (MIQUEL et al, 2004, apud. PAMPLONA, 2009, p. 17).

Identificada a problemática da possibilidade de ausência de articulação de conteúdos matemáticos com a realidade em que se inserem licenciandos(as) e seus(as) professores(as), pensamos em outros possíveis prejuízos não apenas à formação dos(as) licenciandos(as), mas ao próprio trabalho docente do(a) formador(a), que pode nesse caso, efetivar-se mediante uma educação bancária, não humanizadora, feita por meio de comunicados e sem visar à libertação de ambos.

Freire (2018, p. 180) discorre a respeito do papel da ciência (aqui também entendemos a Matemática que é trabalhada nas licenciaturas) voltado a diversos fins, humanizantes ou não, mas nunca neutro e sem interesses:

\footnotetext{
Tanto quanto o desumanismo dos opressores, o humanismo revolucionário implica a ciência. Naquele, esta se encontra a serviço da "reificação"; nesta, a serviço da humanização. Mas, se no uso da ciência e da tecnologia para "reificar", o sine qua desta ação é fazer dos oprimidos sua pura incidência, já não é o mesmo que se impõe no uso da ciência e da tecnologia para a humanização. Aqui os oprimidos, ou se tornam sujeitos, também, do processo, ou continuam "reificados".
}

Pensar nos(as) licenciandos(as) como participantes ativos do processo de ensino, com direito à sua palavra e à compreensão contextualizada do conteúdo, são, dessa forma, estratégias que podem levar a inéditos-viáveis e modificar futuras práticas dos(as) futuros(as) professores(as). Assim, quando pensamos em inéditos-viáveis nas licenciaturas em Matemática levantamos a hipótese de que algumas ações poderiam efetivá-los como a articulação a ser estabelecida pelos(as) formadores(as) entre os conteúdos matemáticos e a transformação da realidade e também o diálogo de todos(as) 
os(as) que constituem os cursos. Os inéditos-viáveis são exemplificados na Pedagogia do Oprimido como formas de levarem os sujeitos oprimidos a perceber suas situaçõeslimites e encontrar estratégias para superá-las:

\begin{abstract}
Em síntese, as "situações-limite" implicam a existência daqueles a quem direta ou indiretamente "servem" e daqueles a quem "negam" e "freiam". No momento em que estes as percebem não mais como uma "fronteira entre o ser e o nada, mas como uma fronteira entre o ser e o mais ser", se fazem cada vez mais críticos na sua ação, ligada àquela percepção. Percepção em que está implícito o inédito viável como algo definido, a cuja concretização se dirigirá sua ação (FREIRE, 2018, p. 130, grifo do autor).
\end{abstract}

Considerando que mencionamos um problema que invade as licenciaturas em Matemática (tanto a formação não-pedagógica de formadores(as) e práticas bancárias em decorrência desta), é preciso também evidenciar o que tem sido feito em prol da formação dialógica e problematizadora dos(as) licenciandos(as). Longe de apontarmos as licenciaturas em Matemática apenas espaços repletos de questões não superadas, compreendemos que muito tem sido feito com e para os(as) estudantes a partir da atuação dos(as) formadores(as).

Selecionamos assim, dois excertos da dissertação de Zero (2020) em que podemos perceber como há docentes que se preocupam em planejar e até modificar suas aulas de acordo com realidade dos(as) alunos(as), abrindo espaço para que o diálogo se desenvolva e também para que elementos sociais que circundam o ensino de Matemática sejam destacados - como pode ser exemplificado na fala da docente ao abordar a presença das mulheres na História da Matemática.

Excerto 2 - Fala do docente Renê - [...] Porque estimulo muito os alunos a trazerem coisas que acontecem em seus ambientes escolares, ou seja, nos próprios ambientes, pois assim, ao mesmo tempo em que tenho aluno que não está fazendo estágio, também tenho aluno que já tem atribuição de aula, inclusive aluno que às vezes participa de plantão de dúvida em colégio particular; às vezes tenho aluno com outra formação anterior, então ele já ministra aula, que às vezes é aula que tem até atribuição dele, então o público é meio diversificado. Eu procuro me apropriar dessa diversidade, vamos dizer assim, do processo de formação do aluno, para inclusive, formar o material para a sala de aula para que essas discussões ocorram em minhas aulas. $O$ universo que nós vivenciamos é muito grande, porque assim como na maioria das instituições públicas, o aluno faz a matrícula por créditos e de acordo com a situação escolar dele. Em meu modo de ver, esse diagnóstico de "que turma eu vou trabalhar" é muito importante, porque dependendo do que eu tenho ali na situação escolar, isso interfere bastante em minhas estratégias de ensino-aprendizagem. Nas primeiras aulas é onde eu vou adequar aquilo que eu planejei inicialmente com o público-alvo que eu tenho na disciplina (ZERO, 2020, p. 61).

Excerto 3 - Fala da docente Sofia- [...] Agora por que entender a estrutura da Matemática é importante para a formação do professor? E eu digo que não só do professor, mas para a formação do professor do licenciando e do bacharelando também, porque às vezes a gente fala muito do licenciando, mas o bacharelando vai formar licenciandos num futuro. Então a gente também tem que ter um cuidado muito grande com a formação desses profissionais para que eles vejam essa questão do ensinar Matemática como uma prática importante. Eu penso que conhecer sobre a estrutura da Matemática é muito importante para o futuro professor, pois ele vai lecionar aquela disciplina. Além disso, em História da Matemática eu tenho uma aula inteira sobre a história das mulheres na Matemática, porque acho que essa é uma discussão importante, as questões de gênero estão aí, muitas vezes a gente ainda reproduz que só homens contribuíram para a Matemática, para o desenvolvimento matemático, uma visão ingênua que não leva em conta que não existia igualdade de condições. Então como é que eu comparo duas coisas diferentes? Como é que eu comparo 


\section{-Revista de Iniciação à Docência, v.6 , n. 2, 2021- \\ Publicação: dezembro, 2021 - ISSN 2525-4332}

laranja com abacate? Não tem como... Como é que eu falo que tem pouca mulher porque elas não se interessam, sem identificar que sim, existiam poucas mulheres ao longo da História porque elas não tinham acesso à educação. Eu penso que esse tipo de discussão é importante tanto para licenciandos, quanto para bacharelandos, porque começa a desmistificar a ideia de que "Matemática é coisa de menino" e essa ideia traz conseqüências para o professor na educação básica, tanto para o professor, quanto para os meninos $e$ para as meninas na educação básica. Eu acho que essa é uma discussão em que o objetivo dela não é esse, mas quando eu a faço, eu tenho esse objetivo também. (ZERO, 2020, p. 61).

$\mathrm{Na}$ fala de Renê é possível apreender a intencionalidade do professor em abrir espaço para que os estudantes falem e tragam elementos de suas vivências pedagógicas: é preciso relembrar que em uma licenciatura temos professores(as) no início de sua formação, ou seja, estes(as) encontram-se possivelmente em espaços escolares tanto nos momentos de estágio, quanto em outras possíveis atividades - no excerto em questão o docente até menciona casos de estudantes que já são professores(as). Além disso, ele não compreende os(as) alunos(as) como um público homogêneo, pois suas características e necessidades moldam seu planejamento e suas práticas. Tal discurso alinha-se à perspectiva dialógica de planejamento pedagógico, pois para Freire (2018, p. 116):

Para o educador-educando, dialógico, problematizador, o conteúdo programático da educação não é uma doação ou uma imposição - um conjunto de informes a ser depositado nos educandos -, mas a devolução organizada, sistematizada e acrescentada ao povo daqueles elementos que este lhe entrou de forma desestruturada.

Em seguida, a fala de Sofia também apresenta dois pontos a serem discutidos: o primeiro, a respeito dos públicos para e com quem o(a) formador(a) pode atuar e o segundo sobre as possibilidades de problematização em conteúdos matemáticos.

Acerca do primeiro ponto, percebe-se que a realidade do(a) formador(a) pode ser encontrada no trabalho com públicos formativos diferentes - licenciandos(as) e bacharelandos(as). Neste caso, também entendemos que muitas vezes se atribui a esse(a) profissional a responsabilização por grande parte da formação específica dos(as)estudantes. Esse ponto nos leva a refletir sobre as condições de trabalho (materiais e humanas) sobrepostas aos(as) professores(as) formadores(as): além da problemática já apresentada sobre a ausência de formação inicial e/ou continuada de caráter pedagógico, como lidar objetivamente na formação de diferentes públicos? É possível atender de forma plena aos distintos anseios formativos de licenciandos(as) e bacharelandos(as)? Seria este um desafio na efetivação do trabalho docente dos formadores? A humanização é discutida como uma necessidade para as futuras práticas de bacharelandos(as) - (visto que estes(as) poderão atuar também na formação de professores(as) - como é o caso de bacharéis que atuam em institutos federais)? O que os cursos podem pensar e fazer a partir dos diferentes objetivos formativos?

A perspectiva humanizadora de trabalho é apresentada em Freire (2018, p. 195): “E que, somente na medida em que os homens criam o seu mundo, que é mundo humano, e 


\section{-Revista de Iniciação à Docência, v.6 , n. 2, 2021- \\ Publicação: dezembro, 2021 - ISSN 2525-4332}

o criam com seu trabalho transformador, eles se realizam. A realização dos homens, enquanto homens, está, pois, na realização deste mundo".

Entendemos dessa maneira, que a prática pedagógica dos(as) formadores(as) faz parte de seu trabalho e para que este seja concebido como transformador, condições precisam ser oferecidas e especificidades estabelecidas, visto que no caso dos(as) licenciandos(as), a ênfase nos conteúdos, articulada ao espaço escolar, deve ser priorizada e em ambos os casos - os(as) de licenciandos(as) e de bacharelandos(as) - se pensarmos na perspectiva da educação libertadora/problematizadora, a Matemática não pode ser trabalhada de forma dissociada da realidade, nem sem visar à transformação revolucionária desta. Pensando na prática docente como parte da formação permanente deste(a) formador(a), recorremos que a Freire (1996, p. 21) afirma que "[...] na formação permanente dos professores, o momento fundamental é o da reflexão crítica sobre a prática. É pensando criticamente a prática de hoje ou de ontem que se pode melhorar a próxima prática”. Komatsu (2010, p. 96), reforça que a pesquisa aliada à formação, atua como facilitadora impulsionando que o futuro professor questione a sua prática, auxiliando-o na busca por solucionar problemas da prática pedagógica "[...] e a atuar de maneira crítica em relação às deliberações das instâncias superiores e às interferências, as quais acontecem nas escolas e no trabalho do professor".

Um dos requisitos para a formação permanente na concepção freireana é o ato de pesquisar, pois:

Enquanto ensino continuo buscando, reprocurando. Ensino porque busco, porque indaguei, porque indago e me indago. Pesquiso para constatar, constatando, intervenho, intervindo educo e me educo. Pesquiso para conhecer o que ainda não conheço e comunicar ou anunciar a novidade (FREIRE, 2005, p. 29).

O último ponto identificado na fala de Sofia denota a viabilidade em se trabalhar conteúdos matemáticos de forma dialética, já que são diversos os fatores que levam à constituição desta ciência. O exemplo da professora vai em direção à participação histórica das mulheres na área matemática. A abordagem feita por ela problematiza uma ideia construída e difundida há muito tempo: "Matemática não é coisa de menino" (conforme fala da docente apresentada no excerto 3) ou em outras palavras: Matemática não é coisa de mulher. A narrativa de Sofia é um exemplo do que é e do que pode ser feito nas licenciaturas em Matemática quando articula-se conteúdos matemáticos e questões sociais a partir da práxis de educadores(as)-educandos(as) e educandos(as)educadores(as). Tal fala da formadora vai na direção da práxis freireana: "A práxis em Freire remete à ideia de um conjunto de práticas visando à transformação da realidade e à produção da história. (CARVALHO; PIO, 2017, p. 428).

A breve análise feita a partir dos dados fornecidos por professores(as) formadores(as) em Zero (2020), mediante o referencial teórico encontrado nas obras de Paulo Freire estudadas pelas autoras, aponta que embora problemáticas existam e incidam no trabalho pedagógico dos(as) formadores(as), há também inéditos-viáveis 


\section{-Revista de Iniciação à Docência, v.6 , n. 2, 2021- \\ Publicação: dezembro, 2021 - ISSN 2525-4332}

(importante conceito do referencial teórico em questão) que podem ser identificados e que mostram a existência da educação libertadora nas licenciaturas em Matemática. Muito ainda pode ser feito, mas já encontramos indícios de que essa pedagogia do diálogo se insere em alguns contextos de formação de professores(as) que ensinam Matemática.

\section{Considerações}

Este trabalho, resultante de muitos momentos dialógicos, de idas e vindas, de contradições pessoais e formativas identificadas, de leituras partilhadas e comentadas, possibilitou mudanças nas ideias que trazíamos e nos sonhos que desejamos concretizar: modificar constantemente nossa práxis em prol da efetivação de uma educação libertadora; buscar implementar oportunidades dialógicas em nossas aulas reconhecendo, dolorosamente, que isso nem sempre se deu em nossa trajetória profissional; e proporcionar um ensino de Matemática mais humano e acessível aos estudantes que por nossas vidas passaram, passam e vão passar, apesar dos nossos limites, tão bem balizadas pelo próprio Freire (2020, p. 39)

Algumas decisões se fizeram unânimes desde o princípio da escrita: consideramos fundamental trazer um breve histórico da vida de Paulo Freire, pois de acordo com nossas vivências e formação como professoras de Matemática, antes da Pós-Graduação, pouco conhecíamos sobre ele, sobre o que havia feito e por onde havia passado. Pensando no possível público que virá a ter acesso a esse material (professores que ensinam Matemática), esse texto pode ser uma porta de entrada para que os(as) leitores(as), em seus diversos papéis assumidos como docentes, se interessem mais pela produção de e sobre Paulo Freire.

Com relação aos objetivos estabelecidos (evidenciar as contribuições teóricas de Paulo Freire para as práticas pedagógicas de formadores(as) de professores(as) que ensinam Matemática e apresentar aos(a) educadores(as) as possíveis inter-relações entre a Educação Matemática e alguns conceitos freireanos em prol da obtenção de subsídios para refletirem sua formação) e à questão de pesquisa proposta (Quais são as principais contribuições teóricas de Paulo Freire para as práticas pedagógicas dos(as) formadores(as) de professores(as) que ensinam Matemática?), entendemos que foram mobilizados importantes conceitos freireanos como inacabamento, práxis, diálogo, reflexão sobre a prática, educação libertadora e inédito viável.

Para estudar e explorar a prática pedagógica dos(as) professores(as) formadores(as) foi necessário ouvi-los, em prol do estabelecimento de uma perspectiva dialógica, e assim os dados encontrados em Zero (2020) deram subsídios às autoras para compreender que tal formador(a) não é universal, possui diferentes trajetórias formativas, leciona distintos conteúdos e disciplinas, adota diferentes abordagens pedagógicas e pode lidar com dois públicos - licenciandos(as) e bacharelandos(as). 


\section{-Revista de Iniciação à Docência, v.6 , n. 2, 2021- \\ Publicação: dezembro, 2021 - ISSN 2525-4332}

Entre os problemas identificados pelos(as) professores(as), destacou-se em nossa análise a possibilidade de uma educação bancária efetivada por docentes que, sem a devida formação pedagógica, podem apenas depositar conteúdos nos(as) licenciandos(as), embora a existência de uma formação pedagógica em outros docentes que atuam nas licenciaturas em Matemática não seja uma regra ou condição para que a educação problematizadora e dialógica se estabeleça.

Como em qualquer pesquisa, mais do que encontrar problemas - formulados em questões - a intenção é buscar caminhos para compreendê-los e superá-los, principalmente quando falamos de uma sociedade invadida por contradições. Dessa maneira, foi possível perceber que práticas dialógicas também são apontadas pelos(as) formadores(as): em dois exemplos (de Renê e de Sofia), os(as) estudantes e suas vivências são considerados horizontalmente no planejamento e na efetivação das aulas, assim como a Matemática também é apresentada de forma situada, histórica e dialética pela professora em questão.

Este trabalho, como um marco na trajetória das autoras, também abre novos desafios a elas e aos(as) leitores(as). Talvez esse público seja composto por pesquisadores(as) que, comprometidos com a análise e com a transformação da realidade em que estão localizados, possam buscar desenvolver novas investigações e propostas de práxis sobre e com os(as) professores(as) formadores(as), sustentadas pelas ideias utópicas, mas também possíveis, de Paulo Freire.

\section{Referências}

CARVALHO, Sandra Maria Gadelha de; PIO, Paulo Martins A categoria da práxis em Pedagogia do Oprimido: sentidos e implicações para a educação libertadora. Revista Brasileira de Estudos Pedagógicos [online]. 2017, v. 98, n. 249, pp. 428-445. Disponível em: https://doi.org/10.24109/2176-6681.rbep.98i249.2729. Acesso em: 08 out. 2021.

CAVALCANTE, Nahum Isaque dos Santos. Formação inicial do professor de matemática: a (in)visibilidade dos saberes docentes. 2011. Dissertação (Mestrado Profissional em Ensino de Ciências e Matemática) - Universidade Estadual da Paraíba, Campina Grande, 2011.

COURA, Flávia Cristina Figueiredo; PASSOS, Cármen Lúcia Brancaglion. Estado do conhecimento sobre o formador de professores de Matemática no Brasil. Zetetiké, v. 25, p. 7, 2017.

FIORENTINI, Dario; PASSOS, Cármen Lúcia Brancaglion; LIMA, Rosana Catarina Rodrigues de. (Org.) Mapeamento da pesquisa acadêmica brasileira sobre o professor que ensina matemática: período 2001 - 2012. Campinas, SP: FE/UNICAMP, 2016.

FORNER, Régis; MALHEIROS, Ana Paula dos Santos. Constituição da práxis docente no contexto da Modelagem Matemática. Boletim de Educação Matemática, v. 34, p. 501-521, ago.2020.

FREIRE, Paulo. Professora sim, tia não: cartas a quem ousa ensinar. São Paulo, Olho D’Água, 1993 a. 
FREIRE, Paulo. Política e Educação. São Paulo, Cortez Editora, 1993b.

FREIRE, Ana Maria Araújo. Apres. In: FREIRE, Paulo. Direitos Humanos e Educação Libertadora: gestão democrática da educação pública na cidade de São Paulo. $2^{a}$ edição. São Paulo: Paz e Terra, 2020a.

FREIRE, Paulo. Pedagogia da autonomia: saberes necessários à prática docente. $31^{\mathrm{a}}$ edição. São Paulo: Paz e Terra, 2005.

FREIRE, Paulo. Pedagogia do Oprimido. $75^{\text {a }}$ edição. São Paulo: Paz e Terra, 202ob.

GADOTTI et al., 1996. Paulo Freire: Uma biobibliografia. São Paulo: Cortez Editora, 1996.

JANZEN, Elen Andrea. O papel do professor na formação do pensamento matemático de estudantes durante a construção de provas em um ambiente de geometria dinâmica. 2011. Tese (Doutorado em Educação) - Universidade Federal do Paraná, Curitiba, 2011.

KOMATSU, Mirna Yshimine. A pesquisa na prática docente de professores formadores: um estudo em um curso de Licenciatura em Matemática. 2010. Dissertação (Mestrado em Educação Matemática) - Pontifícia Universidade Católica de São Paulo, São Paulo, 2010.

LIMA, T. C. S. de; MIOTO, R. C. T. Procedimento Metodológico na Construção do Conhecimento Científico: a pesquisa bibliográfica. Katál, Florianópolis, n. 10, p. 37 - 45, 2007.

MOREIRA, Plinio Cavalcanti. 3+1 e suas (In)Variantes (Reflexões sobre as possibilidades de uma nova estrutura curricular na Licenciatura em Matemática). Boletim de Educação Matemática, Rio Claro (SP), v. 26, n. 44, p. 1137-1150, dez. 2012

OLIVEIRA, Ana Teresa de Carvalho Correa de; FIORENTINI, Dario. O lugar das matemáticas na licenciatura em matemática: que matemáticas, que práticas formativas? Bolema.

Boletim de Educação Matemática, Rio Claro (SP), v.27, 917-938, 2013.

PAMPLONA, Admur Severino. A formação estatística e pedagógica do professor de Matemática em comunidades de prática. 2009. Tese (Doutorado em Educação) Universidade Estadual de Campinas, Campinas, 2009.

PINHEIRO, Ana Cláudia Mendonça. A mediação docente na construção do raciocínio geométrico de alunos da licenciatura em matemática na disciplina desenho geométrico. 2008. Dissertação (Mestrado em Educação) - Universidade Estadual do Ceará, Fortaleza, 2008.

SEVERINO, Antônio Joaquim. Metodologia do trabalho científico. São Paulo: Cortez, 2007.

SHULMAN, Lee S. Conhecimento e ensino: fundamentos para a nova reforma. Cadernos Cenpec | Nova série, [S.I.], v. 4, n. 2, jun. 2015. ISSN 2237-9983. Disponível em: http://cadernos.cenpec.org.br/cadernos/index.php/cadernos/article/view/293. Acesso em: 12 jul. 2021.

STRECK, Danilo Romeu. Paulo Freire e a consolidação do pensamento pedagógico na América Latina. In: STRECK, D. R. (org.). Fontes da pedagogia latino-americana: uma antologia. Belo Horizonte: Autêntica Editora, 2010.

ZERO, Beatriz de Macêdo. Base de conhecimento nas licenciaturas em Matemática: uma análise das concepções dos professores formadores sobre suas práticas pedagógicas. 
-Revista de Iniciação à Docência, v.6 , n. 2, 2021-

Publicação: dezembro, 2021 - ISSN 2525-4332

2020. Dissertação (Mestrado em Educação em Ciências e Matemática) - Universidade Federal de São Carlos, Araras, 2020.

$* * *$

Recebido: 08.08.2021

Aprovado: 14.12.2021 